\title{
Anéis, valsas e carrocéis
}

\section{Introdução}

Como ramo visível das matemáticas a geometria é uma estética que une as ciências com as artes. A ordem pré-determinada do universo que tanto preocupou os clássicos teria a sua origem em relações geométricas. Como encarnação divina a geometria regulava o funcionamento da natureza, enquanto artesãos e artistas, mestres de retábulos e catedrais, davam testemunho da fé através da organização geométrica implícita nas suas obras. Mesmo em épocas vazias de religiosidade a geometria continua a ser um elo de diálogo entre as culturas - muita arte abstracta é entendida como geometria pura, e a visualização e beleza das teorias físicas tem frequentemente um suporte geométrico.

Os Pitagóricos procuravam construir um modelo do universo com base em números e estes derivavam de formas. O problema da quadratura do círculo (equivalência de duas formas perfeitas) estava talvez obscurecido pelo facto de a soma de $\sqrt{2}$ e $\sqrt{3}(=3.1462 \ldots)$ ser aproximadamente igual a $\pi(=3.1416 \ldots)$ - uma coincidência fortuita que levou a muitas pistas falsas. $\sqrt{2} \mathrm{e}$ $\sqrt{3}$ eram os números irracionais fundamentais por aparecerem no triângulo e no quadrado de Platão (Fig. 1).

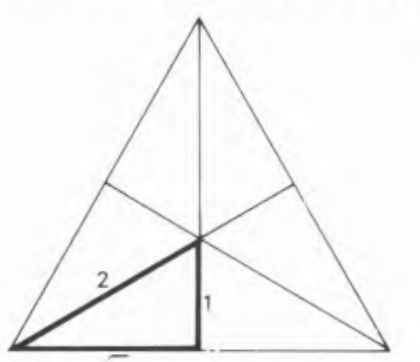

13

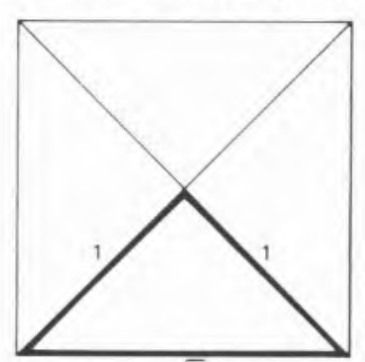

$\sqrt{2}$
Triângulo e quadrado de Platão

Platão discute também os cinco poliedros regulares - tetraedro, octaedro, cubo, dodecaedro e icosaedro - no Timeu e rapidamente eles ficam associados aos quatro elementos de Empédocles.

$$
\begin{aligned}
& \text { Tetraedro - fogo } \\
& \text { Cubo - terra } \\
& \text { Octaedro - ar } \\
& \text { Icosaedro - água }
\end{aligned}
$$

Esta correspondência é um parente distante das teorias de estrutura molecular e da arquitectura das moléculas. $\mathrm{O}$ quinto sólido a mais (dodecaedro, o único c"'jas faces não são triângulos nem quadrados, mas sin pentágonos), foi empurrado para a substância dos corpos celestes. Kepler construiria o seu modelo do universo com base nos poliedros platónicos e assim chegaria à "harmonia das esferas» com conotaçð̄es vincadamente estéticas.
A seguir ao quadrado, o hexágono é o poligono mais "perfeito" - o lado é igual ao raio da circunferência circunscrita. Aparece nos cristais de neve, nos favos de mel (agora muito na moda) e tornar-se-ia num dos símbolos por excelência da Química.

\section{O Ciclo - Da Química à Alquimia}

Para os químicos o hexágono está indelevelmente ligado ao chamado anel do benzeno de Kekulé (1829-1896). A sua descoberta onírica faz hoje parte da mitologia folclórica da química, embora investigaçðes recentes (J.H. Wotiz, S. Rudofskay, Chem. in Britain, 20, 720 (1984), apontem para uma verdade mais prosaica.

-A história seria que a ideia de cadeias de átomos de carbono lhe viera durante um devaneio que experimentara num autocarro em Londres em 1854 ou 1855, enquanto a formulação da estrutura cíclica do benzeno lhe aparecerá em sonhos em Ghent no inverno de 1861 quando se encontrava a dormitar em frente da lareira. Kekulé gostaria que a química fosse um sonho, mas é pelo menos estranho que tivesse esperado uns bons 35 anos antes de revelar a génese da sua inspiração. Por muito cauteloso que fosse (e não nos esqueçamos do seu conselho aos jovens de que «devemos sempre deixar os frutos nas árvores até estarem maduros... Estragam a saúde... os jovens que não sabem distinguir os frutos maduros dos verdes») não é crível que uma fábula tão apetitosa permanecesse no escuro durante tanto tempo. O trabalho original em que pela primeira vez, partindo da tetravalência do carbono - «o carbono é tetratómico (ou tetrabásico)» - Kekulé desenvolve uma teoria de cadeias de átomos, Uber die Constitution und die Metamorphosen der Chemischen Verbindungen und uber die Chemische Natur des Kohlenstoffs (Sobre a Constituição e Metamorfoses de Compostos Químicos e a Natureza Química do Carbono) publicado em 1858, assenta nas ideias de outros químicos coevos, nomeadamente Laurent, que no seu Méthode de Chimie (1854) já introduzira anéis benzénicos hexagonais (Fig. 2).

Os anéis de Laurent são meros auxiliares na visualização dos mecanismos das reacções químicas, mas a sua irregularidade perdurou, por razões tipográficas, mais de cem anos. Em vez do hexágono regular, estudantes de química habituaram-se a ver o anel benzénico alongado e distorcido, conforme mandava a tipografia. Um livro muito em voga nos anos 50 (1950's, entenda-se), dos professores da Universidade de Yale, James

\footnotetext{
a Departamento de Engenharia Química, IST e School of Chemical Engineering, Corneli University.
} 
Pour faire comprendre ce remplacement réciproque de deux restes, je supposerai que, dans l'ammoniaque et le chlorure de benzoile, les atomes sont disposés suivant les figures hexagonales :
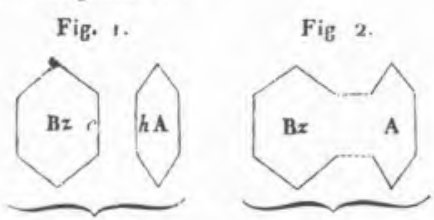

Fig. 3.

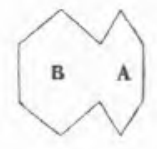

$\mathrm{Bz}$ et A, fig. I, représentent le chlorure de benzoile et l'ammoniaque, au moment oủ ils vont réagir l'un sur l'autre, l'arête $c$ en face de l'arête $h$ qu'elle doit enlever. Bz et A, fig. 2, représentent les deux restes pendant la

Fig. 2

A. Laurent, Méthode de Chimie, Paris, 1854, (pg. 408)

English e Harold Cassidy, apresentava o seguinte aspecto (Fig. 3). A tecnologia da escrita afecta profundamente a nossa maneira de visualizar e entender o mundo.

Os anéis de Kekulé são, porém, verdadeiras estruturas, primeiros edifícios de arquitectura das moléculas. Kekulé, que tinha começado a sua carreıra como estudante de arquitectura, tendo sido desviado para a química pelas aulas brilhantes de Liebig, foi o inventor dos modelos atómicos. É em 1865 que Kekulé dá a lume, com grande pormenor, «os princípios fundamentais duma teoria da substância aromática que concebe[ra] há bastante tempo" - são as três versð̃es do trabalho que marca $o$ anel hexagonal do benzeno, publicadas em França (Bull. Soc. Chim. France 3, 98 (1865)), Bélgica (Bull. Acad. R. Belg., 19, 551 (1865)) e Alemanha (Ann., 137, 129 (1866)). 25 anos mais tarde um grande Festival em Berlim comemora a efeméride (Kekulé tem então 61 anos) - é o Benzol Fest que reuniu discípulos e admiradores, industriais e altas individualidades e que foi largamente coberto pela imprensa. É na versão escrita da reunião, especialmente preparada para os Berichte (23, 1265 (1890)), que Kekulé conta pela primeira vez os seus sonhos de trinta e tal anos antes. «Embarquei num devaneio e, zás, vi os átomos a dar cambalhotas em frente de mim. Até aí sempre que estes seres diminutos me apareciam estavam constantemente em movimento; até então nunca tinha sido capaz de distinguir a natureza do movimento; agora, todavia, reparei como frequentemente dois dos pequenos pegavam em três ou mesmo quatro dos mais pequenos, enquanto o conjunto continuava a rodopiar numa dança de entontecer. Vi como os maiores formavam uma cadeia, arrastando os mais pequenos atrás deles...». A sua descrição do sonho de Ghent, com o fogo a crepitar na lareira e as chamas bruxuleantes a iluminarem-lhe o rosto é ainda mais sugestiva: "Ali estava sentado, a escrever o meu livro de texto, mas não me corria bem, a minha mente deambulava algures. Virei a cadeira para a lareira e fiquei a dormitar. Novamente vi os átomos às cambalhotas diante dos meus olhos. Desta vez grupos mais pequenos mantinham-se na rectaguarda. Os meus olhos, bem treinados por várias visðes do mesmo género, distinguiam agora formações maiores de várias formas. Filas compridas, ligadas mais densamente de diversas maneiras; tudo em movimento, enrolando-se e revolvendo-se como cobras. Mas olha, o que é aquilo? Uma cobra a agarrar a própria cauda, e a forma rodopiou, trocista, à minha frente.
Acordei, como que siderado por um relâmpago; desta vez passei o resto da noite a trabalhar nas consequências do que vira».

Wotiz e Rudofsky no artigo já citado pðem em dúvida não só a veracidade de tais sonhos como o facto de Kekulé os ter referido em público na alocução do Benzol Fest. Como explicar, de outro modo, trinta e cinco anos de divulgação científica (1855-1890) sem a mínima referência aos sonhos de Kekulé, ou o silêncio da imprensa sobre histórias tão saborosas? Há em todo o professor e cientista algo de actor. Não admira que no momento da consagração Kekulé se tenha sentido tentado a embelezar a versão escrita dos acontecimentos, ou a sonhar, à posteriori, sonhos imaginários. A visão romântica da ciência, alimentada por cientistas, é essa mesma: a verdade revelada em fogo de inspiração. Hamilton (1805-1865), o grande matemático irlandês, descreveu assim a génese dos quaterniðes: «Andava a passear a pé em Dublin com a Lady Hamilton e assim chegámos à Ponte Brougham, a que os meus filhos passaram a chamar Ponte dos Quaterniðes, pois foi ai que então senti o circuito galvânico do pensamento a fechar-se, e as faiscas que dai resultaram foram as equaçðes fundamentais entre i, j, k, exactamente como as tenho usado desde então".

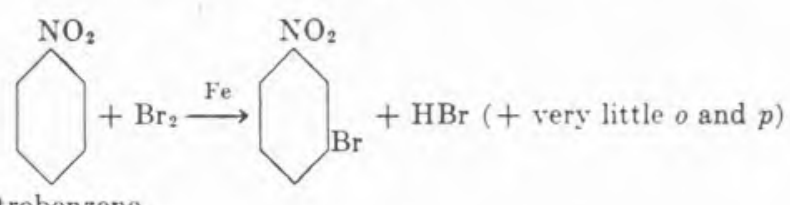

nitrobenzene
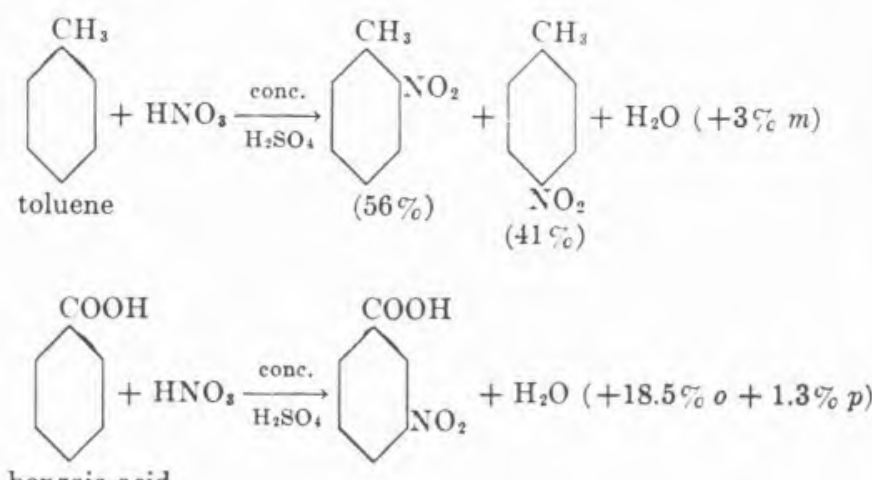

benzoic acid

Fig. 3

J. English, Jr. e H.G. Cassidy, Principles of Organic Chemistry, Mc Graw-Hill, 1949 (parte da pg. 109)

Kekulé poderia muito bem ter-se também lembrado do julgamento em 1847 dum dos mais sensacionais casos-crime da época, o do assassínio da Condessa Gorlitz, que envolveu o roubo de joias célebres incluindo um anel com duas serpentes metálicas entrelaçadas a devorar as próprias caudas. Justus Liebig foi o químico perito chamado a depôr, e Kekulé também apareceu como testemunha.

$\mathrm{O}$ que não passou despercebido aos comentadores foi a associação freudiana com o velho símbolo alquímico ouroboros da serpente a engolir a própria cauda (Fig. 4). A imagem da cobra que eternamente se devora é a metáfora química por excelência da estrutura cíclica que conduziu ao anel do benzeno. Tal como o ouroboros representava a química medieval, o anel benzénico passou a simbolizar a química moderna.

A imortalidade surge primeiro com a caricatura e repete-se depois com o monumento. Em 1886 aparece uma 


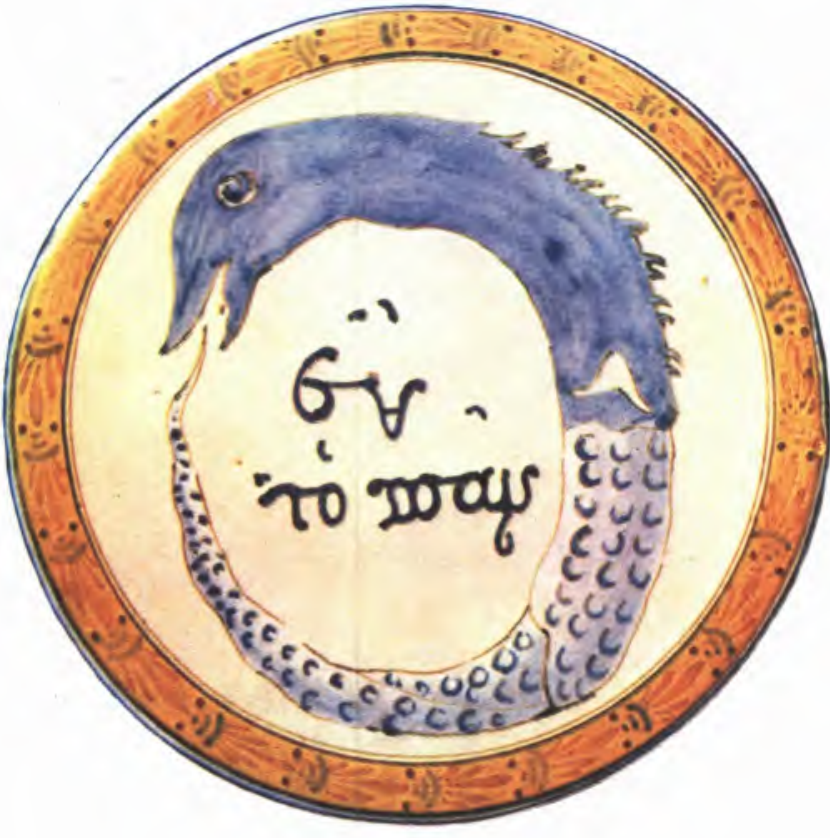

Fig. 4

O simbolo alquímico ouroboros

engraçada publicação, Berichte der Durstigen Chemischen Gesellschaft que reproduzia a tipografia e estilo do afamado Berichte der Deutschen Chemische Gesellschaft mas cujo contéudo era uma sátira à química e aos químicos da época. "Durstigen» significa sedento e ao título talvez não fosse alheio o facto de Kekulé gostar da companhia dos bons copos... Um dos artigos da revista é pretensamente de F.W. Findig (o próprio nome é um achado!) e intitula-se Zur Constitution des Benzols e nele se afirma: "Acho que a Zoologia fornece a ajuda mais perfeita para a compreensão do comportamento dos átomos de carbono... Assim como o átomo de carbono possui quatro afinidades, também os membros da espécie dos "Quatro Membros» possuem quatro mãos que lhes permitem agarrar e pendurar-se noutros objectos. Se se imaginar agora um grupo de seis membros desta família, por exemplo $\mathrm{Ma}$ cacus Cynocephalus (macaco) a estenderem uns aos outros, alternadamente, duas ou uma mão de modo a formar um anel, obtem-se uma analogia muito perfeita com o hexágono do benzeno de Kekulé. Contudo, o acima mencionado Macacus Cynocephalus possui, além das próprias mãos, um apêndice caudal (rabo). Se se tomar isto em consideração, então é possivel ligar os seis indivíduos entre si de outra maneira, formando o anel da figura... Parece-me pois altamente provável que a analogia entre o Macacus Cynocephalus e o átomo de carbono seja completa. Neste caso, todo o átomo-C possui também um apêndice caudal que, embora não possa ser incluído nas afinidades normais, pode no entanto servir para agarrar. Logo que este apêndice, que eu designo por afinidade residual caudal, se torna activo aparece uma segunda forma do hexágono de Kekulé que é obviamente diferente da primeira e tem também um comportamento diferente. Dependendo da situação em que se encontra a molécula de benzeno num dado instante ela assumirá uma ou outra ou ambas as formas, possuindo por isso uma constituição sempre em mudança. Trata-se dum caso especial de tautomerismo que não pode ser entendido de forma mais bonita» (Fig. 5). O manuscrito teria sido recebido na redacção a 31 de Junho, mas mesmo assim houve quem levasse o artigo muito a sério. Anos depois as serpentes encontravam-se misturadas com os macacos nas versðes para a posteridade dos «sonhos» de $\mathrm{Ke}$ kulé.

\section{Viena e as Valsas}

Kekulé fez a sua carreira em Heidelberg, Ghent (Bélgica) e Bonn. Não era vienense mas devia ter sido. Os sonhos de Kekılé, tal como a imaginação de muitos químicos, aparecem permeados pelo Zeitgeist, a visão giratória da valsa. Kekulé fala de átomos «a rodopiar numa dança de entontecer». O seu mestre e amigo $\mathrm{H}$. Kopp (1817-1892) publicou em 1881 um livro original, Aus der Molekular-Welt (Do Mundo Molecular) no qual descreve um "clube imaginário de moléculas» cujo propósito era a dança. Não admira, pois nessa altura tudo e todos dançavam e quase sempre ao som das valsas de Johann Strauss (1825-1899). Clubes, firmas, organizações profissionais - todos tinham os seus bailes anuais (uma praxe que ainda perdura nos nossos dias com o baile anual na ópera de Viena). O Danúbio Azul (1867) transformou-se numa espécie de hino nacional austríaco, e o sucesso de Die Fledermaus (1874) estava também no ritmo rodopiante que era o da Viena do seu tempo.

A figura da valsa é a circunferência (o ciclo) e o seu poder encantatório tinha qualquer coisa de dionisíaco que bulia com a moral da época (tal como o "charleston», o «twist», o «rock», etc., das geraçðes posterio-

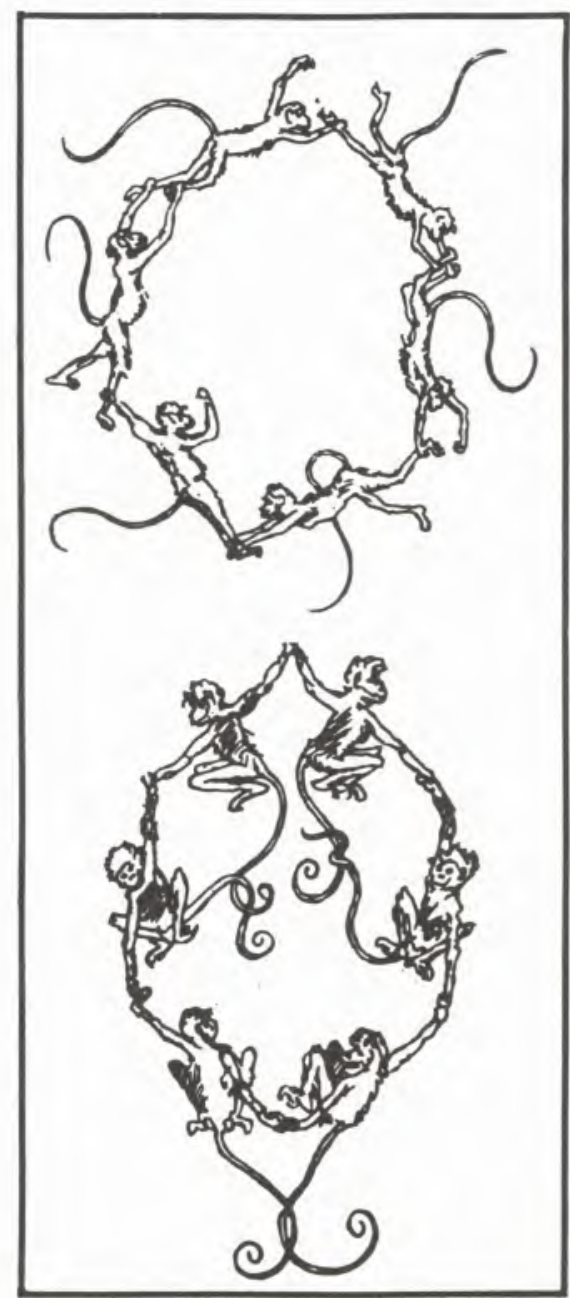

Fig. 5

As estruturas de macacos em Berichte der Durstigen Chemischen Gesellschaft 
res). Um visitante de Viena descreveu Strauss e a sua cena duma forma muito expressiva: "Africano e de sangue quente, louco com vida... exorciza os diabos malévolos dos nossos corpos e fá-lo com as valsas, que são o exorcismo moderno... capturando os nossos sentidos num transe doce. Tipicamente africana é a maneira como dirige as suas danças; os seus próprios membros deixam de lhe pertencer quando a trovoada da valsa põe à solta; o arco do violino dança com os braços... o andamento anima os pés; a melodia ondula taças de champanhe em frente da cara e o demónio foi para o estrangeiro... Um poder perigoso foi posto nas mãos deste homem escuro... Os casais valseiam bacantemente... A luxúria anda à solta. Não há Deus que os detenha».

O poder libertário da dança tem algo a ver com a estrutura sem começo nem fím da roda circular - o ciclo fechado. Quando Matisse pinta em 1909 a sua Danse (um tema que o interessaria pela vida fora) utiliza uma composição cíclica de cinco bailarinas nutridas à la Isadora Duncan no plano espalmado da tela (a Duncan tinha um estúdio de dança no mesmo edifício onde Matisse tinha o seu "atelier») (Fig. 6). É curioso que a versão original da Danse surge no grupo bailarino do plano de fundo da sua Bonheur de vivre (1905-06), desta vez com seis membros tal como no benzeno... Ao crítico americano Charles Caffin que notou que o efeito produzido pela Danse «é barbárico... contribuindo para a expressão primitiva, elemental, quase rudimentar do conjunto" Matisse explicou que neste caso «a organização e simplificação foram pensadas de modo a produzir uma expressão de abandono puramente físico de formas sensuais até atingir a intoxica- ção». Esta é afinal a linguagem da valsa e, filtrada pelo racionalismo científico, é também a dos sonhos de Kekulé.

$\mathrm{Na}$ segunda metade do século XIX o ciclo estava na ordem do dia, e não só na química dos aromáticos e corantes. Paris foi reconstruída radialmente, com os novos «boulevards» a divergir centrifugamente de L'Étoile; Manhattan cresceu como uma grelha cartesiana rectangular. Pelo contrário, a renovação urbanística de Viena dá-se com a abertura da Ringstrasse, o amplo anel circular que envolve a parte velha da cidade (completado nos anos sessenta).

Ficou reservado ao dramaturgo vienense Arthur Schnitzler (1862-1931) transpôr para o teatro o espírito do anel vienense - a sua peça Reigen (1896), mais conhecida pelo título francês $L a$ Ronde, tem estrutura cíclica e assunto escabroso - uma série de pecinhas em diálogo, cada uma delas terminando na cópula sexual, em que cada episódio retém um dos parceiros do anterior. Os acasalamentos são como se segue:

1. prostituta + soldado

2. soldado + criadinha de fora

3. criadinha de fora + jovem cavalheiro

4. jovem cavalheiro + jovem esposa

5. jovem esposa + marido

6. marido + menina

7. menina + poeta

8. poeta + actriz

9. actriz + conde

10. conde + prostituta

A prostituta da última cena é também a que introduz a peça na primeira. Sabemos já que a roda é libidinosa,

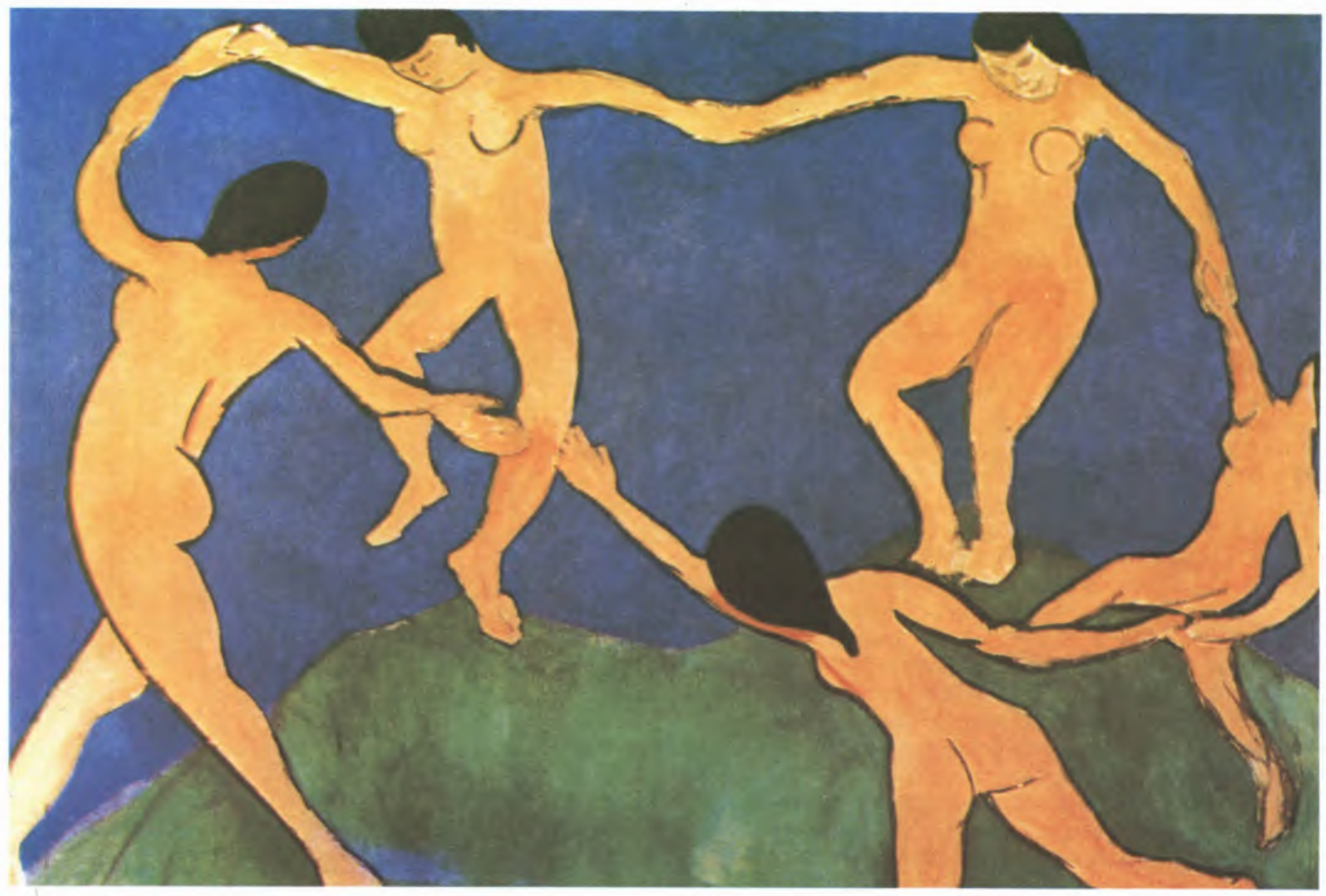

Fig. 6

Henri Matisse, Danse (I), 1909 


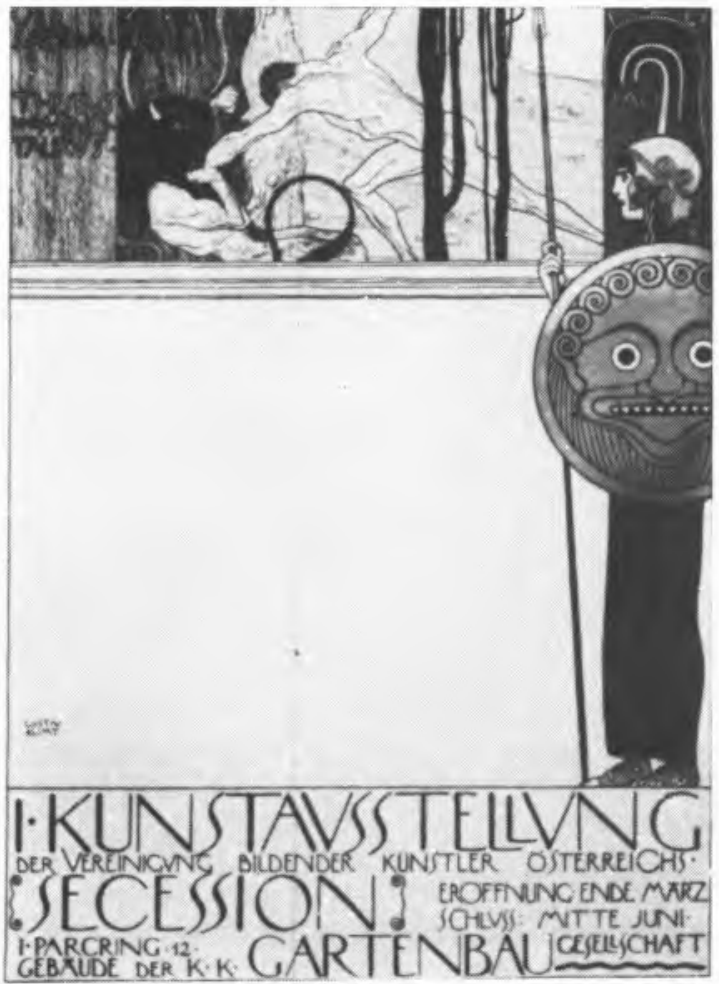

Fig. 7

Gustav Klint, Cartaz para a $1 .{ }^{a}$ Exposição da «Wiener Secession» em 1898

e o resultado foi um escândalo que levou Schnitzler a proibir a representação da peça. (O «copyright» só foi levantado 50 anos após a morte do autor, em 1982). Recentemente em Lisboa Ricardo Pais encenou outra série de pecinhas de Schnitzler, Anatol (1888 em diante) e deu-lhe apropriadamente estrutura cíclica, partindo Manhã de Casamento de Anatol ao meio e usando as duas metades para abrir e fechar o espectáculo.

Cecil B. de Mile pôs Anatol em cinema, mas foi Max Ophuls quem se revelou o mais schnitzleriano (para não dizer vienense) dos cineastas. A sua versão de $L a$ Ronde (1950) reflecte as simetrias subjacentes à obra quando, logo no início, o líder do jogo (desempenhado por Anton Walbrook) fez rodar o carrocel ao ritmo insidioso de uma valsa de Oscar Strauss: "Tournent, tournent mes personages!».

E a roda continuou a rodar. Como a circunferência, o Finnegan's Wake (1922-39) de Joyce não tem princípio nem fim - começa a meio e acaba a meio; a última frase engrena ciclicamente na primeira: «riverrun, past Eve and Adam's, from swerve of shore to bend of bay, brings us by a commodius vicus of recirculation back to Howth Castle and Environs» / "A way a lone a last a loved a long the» / "riverrun, past Eve and Adam's..." e por aí fora, como programa mal programado em que não é possível sair do «loop».

\section{Epílogo - O Centro vazio}

No final do século o anel omnipotente de Viena tinha adquirido um novo significado - o de que a existência era periférica e que o centro estava vazio. $\mathrm{O}$ cartaz que Gustav Klint (1862-1918) desenhou para a primeira exposição da "Wiener Secession" em 1898 chocou não só porque na primeira versão faltavam os ramos estrategicamente colocados para esconder a genitália de Teseu, mas principalmente pelo arrojo em deixar vazio o espaço imenso do centro (Fig. 7). É esta a característica da estrutura cíclica que o "design» do cartaz de certo modo assemelha. O mesmo se passa com os estilos decorativos da época - os ornamentos centrífugos da arte nova, espraiando-se ondularmente pela periferia das coisas, desviando a atenção do centro que não existe. A decoração tornou-se importante porque era inteiramente desnecessária e até moralmente condenável. A arquitectura despida e puritana dum Adolf Loos é a condenação dos impulsos eróticos associados à licenciosidade da decoração excessiva.

Coube ao engenheiro Robert Musil (1880-1942) retratar esta Viena sem sentido do princípio do século. A sua obra-prima Der mann ohne Eigenschaften (O Homem sem Qualidades) é isso mesmo, o retrato dum homem sem centro e sem vontade, uma simples soma de atributos e qualidades como a decoração duma folha de imprensa de arte nova (Fig. 8).

$\mathrm{Na}$ música a frase melódica atomizada pelo cromatismo, quebra-se nos intervalos e silêncios do atonalismo. Com a queda do Império Austro-Húngaro, a Europa Central deixa de justificar o adjectivo - o centro é apenas geográfico, e o poder mudou-se para algures. Em 1909 Rutherford observa o impossivel: partículas $\alpha$ a ser reflectidas por folha fina de ouro. No ano seguinte ele já sabia o que era um átomo - um núcleo minúsculo carregado positivamente, rodeado por electrðes a dançar a valsa em órbitas circulares. Mais: à maior parte do espaço material era espaço vazio - «a maior revolução na nossa concepção da matéria desde o tempo de Demócrito", no dizer de Eddington.

O ciclo permanece. Repetitivo, sem princípio nem fim, é a visão do eterno. Nas modernas teorias cosmológicas o ciclo marca a contagem do tempo.

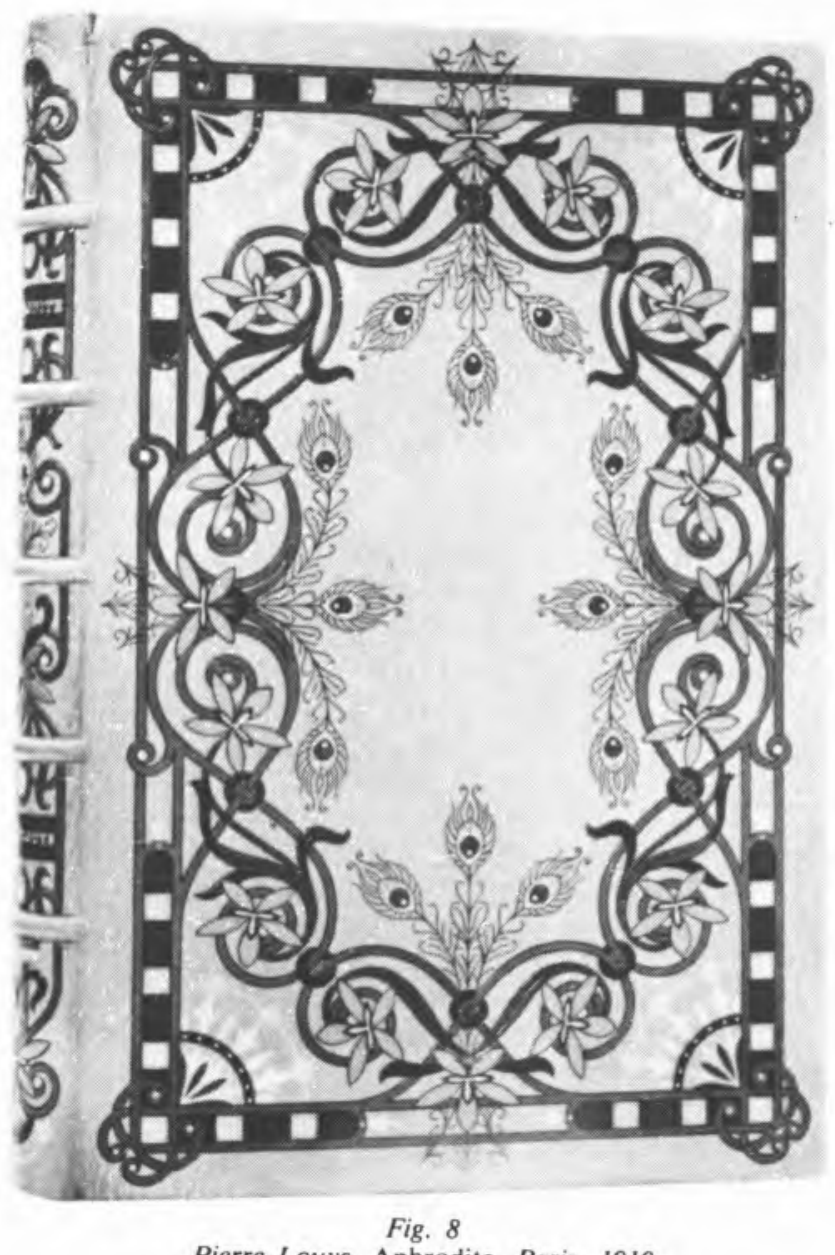

Pierre Louys, Aphrodite, Paris, 1910 